\title{
Breadth of pictorial and verbal codes in memory
}

\author{
BARBARA TVERSKY* \\ Hebrew University, Jerusalem, Israel
}

\begin{abstract}
The breadth of pictorial and verbal encoding modalities was examined by using reaction times to a same-different task in bilinguals. For each of the four geometric figures, there were two pictorial representations, outline or filled drawings, and two verbal representations, the figure names in two languages. While the pictorial code was broad enough to allow unmediated comparison of two pictures with no visual components in common, the verbal code was not semantic, as had been previously maintained, and did not allow direct comparison of equivalent words in different languages.
\end{abstract}

While it has been repeatedly demonstrated that both verbal and pictorial codes of the same stimuli are functional in memory (Brooks, 1968; Frost, 1972; Posner, Boies, Eichelman, \& Taylor, 1969; Smith \& Nielsen, 1971; Tversky, 1969), the breadth of each of these codes has not been directly examined. One way of determining the breadth of a code is to examine the range of exemplars which are rapidly compared; additional time is necessary to compare stimuli encoded in different modalities. For instance, when schematic faces are pictorially encoded, but a verbal comparison is required, or when they are verbally encoded, but a pictorial comparison is required, comparison times increase by more than $150 \mathrm{msec}$ over situations in which encoding modality matches comparison modality (Tversky, 1969). Since comparison time increases when encoding and comparison modalities differ for both "same" and "different" responses, this finding cannot be attributed to a simple test of match or mismatch. Rather, the processes of comparison seem to take place within a modality, so that when stimuli to be compared are in different modalities, one stimulus must first be recoded or transformed to the modality of the other in order to execute the comparison. Tversky (1969) presented evidence that the stimulus, face or name, in memory is recoded into the modality of the presented stimulus, pictorial or verbal, while Clark and Chase (1972) presented evidence that simultaneously presented sentences and pictures are both propositionally encoded in order to make a true-false judgment.

An interesting question then arises: how different can two stimuli be and still be compared without transformation? For instance, are two pictures which are equivalent in meaning yet share no physical properties, e.g., an outline picture vs a filled-in picture, compared directly? And are two words equivalent in meaning yet sharing no physical properties, e.g., a word and its translate, directly compared via a semantic code, or is

\footnotetext{
*This research was performed while the author held a postdoctoral fellowship from the National Institu te of Mental Health at Stanford University. It was also supported by the Advanced Projects Research Agency, United States Department of Defense, monitored by the United States Air Force Office of Scientific Research under Contract F44620-670-C-0099 at the University of Oregon. The author expresses their appreciation to Steve Peskind for his devoted assistance in the research.
}

encoding limited to one language or another? Each of the four geometrical stimuli of the present experiment has two pictorial-filled and outline-and two verbal-English and Hebrew-representations. For any session, the first stimulus, either pictorial or verbal in blocks, is processed and stored in memory. The second stimulus for any session is either pictorial or else verbal for $83 \%$ of the trials; for $17 \%$ of the trials, at random, the stimulus modality is changed. Thus, it is to the S's advantage to encode and store the first stimulus in the expected modality of the second. If the Ss succeed in encoding in the expected modality, either pictorial or verbal, then there should be a marked increase in comparison time on those few trials in which the modality is contrary to expectation. If not, that is, if pictorial encoding is limited to style of illustration and not more abstract and/or if verbal encoding is limited to language of presentation and not semantic, then there should be no advantage in comparison time from fore-knowledge of the comparison modality.

There is evidence from a variety of tasks for involuntary interference as well as facilitation of word-translate pairs from the languages of bilinguals, indicating close relationships within word-translate pairs despite the ability to keep languages separate. In the Stroop task, for instance, where Ss are required to call out quickly the colors of the ink in which words are printed, Ss are slower when the words are color names in another language than rows of Xs, and even slower when the words are noncongruent color names in the other language (Dalyrymple-Alford, 1968). Hamers and Lambert (1972) found similar results in an acoustic version of the Stroop, where bilingual Ss reported, either vocally or by a keypress, the pitch, high or low, of a tone or word, where the word was "high" or "low," spoken in French or in English, and in either the appropriate pitch or incompatible pitch. Ss' verbal responses were faster where they responded in a language different from the stimuli than where stimuli and responses were compatible and in the same language, and these responses were faster than where stimuli and responses were incompatible (e.g., low-pitched voice saying "high"). Thus, in speeded tasks where it is to Ss' advantage to ignore semantic aspects of words, and 
Table 1

Design of Experiment

\begin{tabular}{|c|c|c|c|c|c|c|}
\hline \multirow[b]{2}{*}{$S$} & \multirow{2}{*}{$\begin{array}{l}\text { "Same" } \\
\text { Hand }\end{array}$} & \multirow{2}{*}{$\begin{array}{c}\text { Trial } \\
\text { Blocks }\end{array}$} & \multicolumn{4}{|c|}{ Session } \\
\hline & & & 1 & 2 & 3 & 4 \\
\hline 1 & Left & $\begin{array}{r}1-48 \\
49-96\end{array}$ & $\begin{array}{l}\text { P-P } \\
\text { V-P }\end{array}$ & $\begin{array}{l}\text { P-V } \\
\text { V-V }\end{array}$ & $\begin{array}{l}\text { V-V } \\
\text { P-V }\end{array}$ & $\begin{array}{l}\text { V-P } \\
\text { P-P }\end{array}$ \\
\hline 2 & Right & $\begin{array}{r}1-48 \\
49-96\end{array}$ & $\begin{array}{l}\text { P-V } \\
\text { V-V }\end{array}$ & $\begin{array}{l}\text { P-P } \\
\text { V-P }\end{array}$ & $\begin{array}{l}\text { V-P } \\
\text { P-P }\end{array}$ & $\begin{array}{l}\text { V-V } \\
\text { P-V }\end{array}$ \\
\hline 3 & Left & $\begin{array}{r}1-48 \\
49-96\end{array}$ & $\begin{array}{l}\text { V-V } \\
\text { P-V }\end{array}$ & $\begin{array}{l}\text { V-P } \\
\text { P-P }\end{array}$ & $\begin{array}{l}\text { P-P } \\
\text { V-P }\end{array}$ & $\begin{array}{l}\text { P-V } \\
\text { V-V }\end{array}$ \\
\hline 4 & Right & $\begin{array}{r}1-48 \\
49-96\end{array}$ & $\begin{array}{l}\text { V-P } \\
\text { P-P }\end{array}$ & $\begin{array}{l}\text { V-V } \\
\text { P-V }\end{array}$ & $\begin{array}{l}\text { P-V } \\
\text { V-V }\end{array}$ & $\begin{array}{l}\text { P-P } \\
\text { V-P }\end{array}$ \\
\hline
\end{tabular}

Note-P-V denotes that the first stimulus is pictorial and the second stimulus verbal.

attend to only the physical aspects, Ss are unable to ignore semantic properties of words even when the words are in a different (but familiar) language. Similar effects have been found in memory tasks. In a paired-associate learning task, using English and German words as stimuli and numerical responses, Kintsch and Kintsch (1969) found interference between words and their translates. Kolers (1966) presented long lists of English and French words for free recall, repeating items within the list either in the same or different language. He found that the probability of recalling an item increased equally whether the item was repeated in the same or different language, and concluded that "S stores items in terms of their semantic, not their morphemic properties [p. 318]."

In line with the conclusion that items are stored in terms of their semantic properties are certain impressions commonly reported by bilinguals. For instance, they report that they often conduct conversations with no awareness or later recall of the language of conversation, or that they search through a pile of mail addressed in two languages with different alphabets for their own name irrespective of the alphabet. The author conducted an informal survey of Hebrew-English bilingual faculty members at mail time, asking "When you look through a pile of mail addressed in Hebrew and English, how do you search for your own mail?" All but 3 of 13 respondents ( $<<.05$, sign test) reported that they search for their name, and that it "stands out" in either language. The other three replied that they only looked through the English mail because the Hebrew wasn't likely to be important.

The present experiment, described schematically above, was designed to examine the breadth of verbal and pictorial codes. Specifically, can two words equivalent in meaning but in different languages, or two pictures equivalent in meaning but with different visual representations, be directly compared, or must one word or picture be transformed to the representation of the other in order to make a comparison?

\section{METHOD}

\section{Subjects}

The Ss were four Stanford students, native Hebrew speakers, who were paid for their participation in four experimental and one control session of about $1 \mathrm{~h}$ each.

\section{Stimuli}

The stimuli were the words square, rectangle, circle, and lens written in English and in Hebrew and two sets of pictures of these objects, either outline drawings or drawings with no outline but filled in by clusters of small open circles of various sizes. The word lens was chosen instead of ellipse for the elliptical figure because the Hebrew word for ellipse is essentially a transliteration, and this was not true of any of the words chosen for the experiment. Both Hebrew and English words were printed in a similar typeset of Letraset letters, the line figures were drawn in black ink, and the dot figures were filled in by Letratone LT 181. A pair of stimuli were "same" if the same figure was referred to, regardless of language or style of illustration, and "different" if different figures were referred to.

\section{Procedure}

On any particular trial, the $S$ saw, in a three-field Iconix tachistoscope, the first stimulus for $1 \mathrm{sec}$, followed by a blank field for $1 \mathrm{sec}$, followed by the second stimulus which stayed in view until S responded "same" or "different" by pressing one of two keys with his index finger. For half the Ss, the right key signified "same" and for half the left key signified "same." Then $S$ received feedback while E prepared the stimulus cards for the next trial. There were 96 experimental trials in two blocks of 48 trials each, with 8 practice trials before each block. At the beginning of each session, $\mathrm{S}$ was informed of the ex act structure of the stimuli for that session, and reminded of the changes in structure before the second block. S was told to respond as quickly as possible without making errors; if $\mathbf{S}$ began making many errors during a session, he was asked to slow down in order to reduce errors. Trials on which an error was made were repeated after a Pag of 5 or 6 trials. If an error was made again, the trial was not repeated a third time.

\section{Design}

During any particular session, the second stimulus was always either a picture or a word on $83.3 \%$ of the trials. On the other $16.6 \%$ of the trials, called "surprise" trials, the second stimulus was presented in the other modality. Thus, Ss were encouraged to encode the first stimulus in the expected or dominant modality of the second stimulus. For one block of each session, the first stimulus was always pictorial, while for the other block, the first stimulus was always verbal. Each S had these conditions in a different order. For half the Ss, the first and fourth sessions had pictures as second stimuli on most trials, and the second and third sessions had words as dominant second stimuli, in order to spread practice effects. For the other Ss, order was reversed. Half of each of the above groups began the first day's session with the first stimulus modality different from the second (pictorial-verbal or verbal-pictorial), and the other half began the first session with both stimuli of the same modality. For the second block, conditions were reversed. Likewise, Ss who had begun with a pure block at the first session, began with a mixed block in the second session, returned to a pure block in the third session, and a mixed block for the final experimental session. For those beginning with a mixed block, conditions were reversed. The experimental design is illustrated in Table 1.

Within each experimental session, half the pair types were "same" and half "different." Each figure appeared equally of ten as first and as second stimulus for both cases, "same" and "different." Order of trials was randomized. Surprise trials were chosen such that half were "same" and half "different," so that stimulus types appeared equally often, and so that a surprise trial did not follow a surprise trial. Within those constraints, surprise trials were randomly selected.

The fifth session was a control session, with second stimuli always lines or dots or Hebrew or English in four blocks and with no surprise trials, to assess the relative ease of the 
modalities and their representations. The first stimuli were randomly of each type. Again, half the pairs were "same," half "different," and each figure occurred with equal frequency. Block types were counterbalanced across Ss.

\section{RESULTS}

Mean reaction times by first and second stimulus modalities and "same" or "different" responses are displayed in Table 2 for nonsurprise trials and in Table 3 for surprise trials. Errors, which constituted less than 5\% of the trials, were omitted from all analyses. Separate analyses of variance for nonsurprise and surprise trials with these variables plus trials as factors were computed. For nonsurprise trials there was a significant decrease in reaction time over trials $[\mathrm{F}(39,117)=3.44, \mathrm{p}<.01]$, and responses to second pictures were significantly faster by an average of $131 \mathrm{msec}$ than responses to second words $[F(1,3)=12.19, p<.05]$. No other effects or interactions of effects were significant. An analysis of variance was used to compare responses to second pictures on surprise trials with nonsurprise trials. Ss were, on the average, $135 \mathrm{msec}$ slower to respond to second pictures on surprise trials, a highly significant effect $[F(1,760)=96.3, p<.001]$; within-S differences were also significant $[F(1,760)=7.5, p<.001]$. For second words, there was essentially no difference between surprise and nonsurprise trials, with performance on nonsurprise trials as slow as performance on both second stimulus modalities for surprise trials.

On nonsurprise trials, responses to second words were significantly faster $(t=2.63, p<.01)$ when words were Hebrew (average of $539 \mathrm{msec}$ ) than when the words were English $(577 \mathrm{msec})$. For second pictures, there was essentially no difference in reaction time to outline pictures $(428 \mathrm{msec})$ and to dotted pictures $(425 \mathrm{msec})$.

Mean reaction times for control days, in which the second stimulus was always English or Hebrew or outline

Table 2

Mean Reaction Times in Milliseconds on Nonsurprise Trials

\begin{tabular}{cccc}
\hline & & \multicolumn{2}{c}{$\begin{array}{c}\text { Second Stimulus } \\
\text { Modality }\end{array}$} \\
\cline { 3 - 4 } & & Pictorial & Verbal \\
\hline \multirow{2}{*}{ First Stimulus Modality } & Pictorial & 410 & 555 \\
& Verbal & 443 & 560 \\
Second Stimulus Means & 427 & 558 \\
\hline
\end{tabular}

Table 3

Mean Reaction Times in Milliseconds on Surprise Trials

\begin{tabular}{cccc}
\hline & \multicolumn{2}{c}{$\begin{array}{c}\text { Second Stimulus } \\
\text { Modality }\end{array}$} \\
\cline { 3 - 4 } & Pictorial & Verbal \\
\hline \multirow{2}{*}{ First Stimulus Modality } & Pictorial & 565 & 554 \\
& Verbal & 558 & 567 \\
Second Stimulus Means & 562 & 561 \\
\hline
\end{tabular}

Table 4

Mean Reaction Times in Milliseconds on Control Days

\begin{tabular}{llcc}
\hline & & \multicolumn{2}{c}{$\begin{array}{c}\text { Second Stimulus } \\
\text { Modality }\end{array}$} \\
\cline { 3 - 4 } & & Pictorial & Verbal \\
\hline \multirow{2}{*}{ First Stimulus Modality } & Pictorial & 339 & 372 \\
& Verbal & 337 & 386 \\
\hline
\end{tabular}

or dotted pictures in blocks, are reported in Table 4 . When the exact form of the second stimulus is known ahead of time, there are no significant differences in reaction time due to the first stimulus. Second pictures, with a mean reaction time of $338 \mathrm{msec}$ are responded to considerably faster $(\mathrm{t}=4.63, \mathrm{p}<.001)$ than second words with a mean reaction time of $380 \mathrm{msec}$. There were no differences in reaction time attributable to the two pictorial representations or to the two verbal representations as either first or second stimuli.

\section{DISCUSSION}

The results, then clearly support a single pictorial modality for the two pictorial representations, but fail to support a single semantic modality for the two linguistic representations. Knowing that the second stimulus will probably be a picture speeds comparison times to pictorial as opposed to verbal second stimuli, but knowing that the second stimulus will probably be a word does not speed comparison times to second words over pictures. Moreover, reaction time to second expected verbal stimuli is virtually identical to the reaction time to unexpected verbal stimuli, as well as to unexpected pictorial stimuli. The additional time required to respond to an unexpected word, $135 \mathrm{~m} \mathrm{sec}$, is only slightly less than the $150 \mathrm{~m} \mathrm{sec}$ obtained in a previous experiment (Tversky, 1969) which used more complex stimuli and obtained higher overall reaction times. This additional $100-150 \mathrm{msec}$ is presumably the time required to recode or transform the stimulus in memory to the modality of the second stimulus. Thus, in a speeded comparison task, mental representations of pictorial stimuli are broad enough to include two pictorial representations with no visual parts in common, yet mental representations of words seem to be language-specific and not semantic. This conclusion is further supported by the finding that when the second stimulus was pictorial as expected, Ss responded equally quickly whether the stimulus was outline or dotted, whereas when the second stimulus was verbal as expected, there was a large advantage in reaction time to stimuli in the Ss' native language, Hebrew. No advantage to native language was evident during the control days, where Ss could correctly anticipate the particular language or verbal representation of the second stimulus.

The finding that an abstract pictorial modality underlies comparison of two visual representations is consistent with research findings that the recognition and discrimination of visual patterns is aided by abstraction of prototypes or schemas. Posner and Keele (1968), for instance, found that after learning a set of patterns which are distortions of a prototype, Ss are more efficient at recognizing the prototypes on initial viewing than distortions also viewed for the first time, and in some cases are more efficient recognizing the newly viewed prototype than the old distortions. The present stimuli, however, are special in that instead of being distortions produced by altering some but not all of the visual features, these stimuli have essentially no visual features in common. What is shared by the two visual representations is their abstracted visual contours, which Attneave (1954) demonstrated to be important in visual perception and memory. 
The failure to find an abstract semantic modality underlying rapid comparisons of two verbal representations does not rule out the possibility that under different circumstances, words are responded to and/or processed semantically over and above specific languages. However, the evidence presumably supporting automatic interference and facilitation between translates in bilinguals presented in the first part of the paper derives either from memory experiments where relatively large periods of time are allotted to Ss to encode and transform the words or else from variations of the Stroop task, which although speeded, deliberately arouse the conflicting translate. Although the present task encouraged Ss to encode words semantically, Ss were apparently unable to do so in making rapid comparisons. Thus, there does not seem to be evidence that words automatically and immediately arouse their translates or that words make direct rapid contact with a semantic system.

\section{REFERENCES}

Attneave, F. A. Some informational aspects of visual perception. Psychological R eview, 1954, 61, 183-193.

Brooks, L. R. Spatial and verbal components of the act of recall. Canadian Journal of Psychology, 1968, 22, 349-368.

Clark, H. H., \& Chase, W. G. On the process of comparing sentences against pictures. Cognitive Psychology, 1972, 3, 472-517.

Dalyrymple-Alford, E. C. Interlingual interference in a color-naming task. Psychonomic Science, 1968, 10, 215-216. Frost, N. Encoding and retrieval in visual memory task. Journal of Experimental Psychology, 1972, 95, 317-326.

Hamers, J. F., \& Lambert, W. E. Bilingual interdependencies in auditory perception Journal of Verbal Learning \& Verbal Behavior, 1972, 11, 303-310.

Kintsch, W., \& Kintsch, E. Interlingual interference and memory processes. Journal of Verbal Learning \& Verbal Behavior, $1969,8,16-19$.

Kolers, P. A. Interlingual facilitation of short-term memory. Journal of Verbal Learning \& Verbal Behavior, 1966, 5, 314-319.

Posner, M. I., Boies, S. J., Eichelman, W. H., \& Taylor, R. L. Retention of visual and name codes of single letters. Journal of Experimental Psychology Monograph, 1969, 79, 1-16.

Posner, M. I., \& Keele, S. W. On the genesis of abstract ideas. Journal of Experimental Psychology, 1968, 77, 353-363.

Smith, E. E., \& Nielsen, G. D. Representations and retrieval processes in short-term memory: Recognition and recall of faces. Journal of Experimental Psychology, 1970, 85, 397-405.

Tversky, B. Pictorial and verbal encoding in a short-term memory task. Perception \& Psychophysics, 1969, 6, 225-233.

(Received for publication April 17, 1974.) 